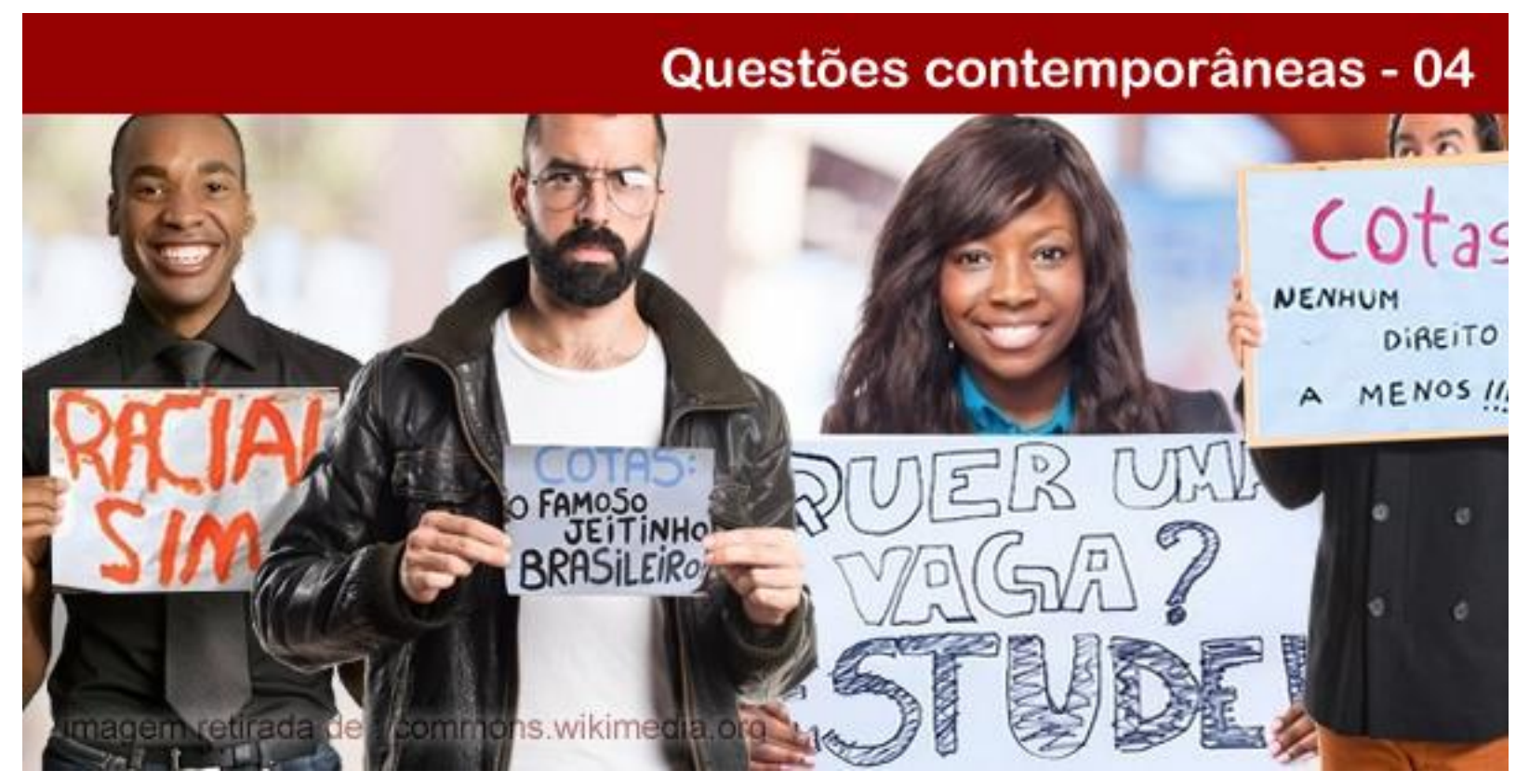

\title{
A RATIONALE DOS POSICIONAMENTOS ACERCA DAS COTAS: UM LEVANTAMENTO TEÓRICO E EMPÍRICO DE ESTUDOS BRASILEIROS NO SÉCULO XXI
}

\section{Thamiris Marques}

Psicóloga. Professora do Departamento de Fundamentos de Psicologia no Instituto de Psicologia da Universidade do Estado do Rio de Janeiro (UERJ). Doutoranda em Psicologia Social pela UERJ. Email: thamiris_marques@hotmail.com.

\section{Álvaro Rafael Santana Peixoto}

Mestrando em Psicologia Social e graduado em Psicologia pela Universidade do Estado do Rio de Janeiro (UERJ).E-mail: alvarorafael.peixoto@gmail.com.

\section{Rafael Pecly Wolter}

Professor do Programa de Pós-Graduação em Psicologia da Universidade Federal do Espírito Santo. Pósdoutorado pela Universidade do Estado do Rio de Janeiro (UERJ) e Doutor em Psicologia pela Université Paris Descartes, Paris V, França. E-mail: rafaelpeclywolter@gmail.com.

Resumo: Este artigo propõe uma discussão acerca dos posicionamentos relativos às cotas. Foi realizada uma revisão de literatura com a finalidade de levantar argumentos favoráveis e contrários às cotas, oriundos de estudos de quatro áreas das Ciências Humanas (psicologia social, antropologia, sociologia e educação) realizados no Brasil a partir dos anos 2000 com enfoque no posicionamento de estudantes universitários. Constatou-se que os argumentos desfavoráveis ao sistema de reserva de vagas estão calcados, principalmente, em problemas decorrentes da vigência da medida, enquanto nos argumentos favoráveis encontram-se a eficácia das cotas e sua finalidade de reparo histórico-social. Foram levantadas possíveis causas que levam grupos de pessoas a se posicionar em relação às cotas: a primeira causa está relacionada com as experiências individuais prévias, que ocorrem quando o fato de conviver ou presenciar discriminação em relação a minorias marca os indivíduos e faz com que possuam posicionamento favorável ou contrário acerca do tema; a segunda causa corresponde ao direito ao benefício, já que o fato do sujeito poder ou não se beneficiar das cotas traria uma influência no posicionamento que tem da medida. A terceira causa seria a proximidade com os cotistas, que corresponde à aproximação do sujeito com pessoas do círculo pessoal que são cotistas; a quarta causa seria a homologia estrutural, de modo que

\section{POLÊM!CA $\mid$ LABORE (}

Polêmica - Revista Eletrônica da Uerj - Rua São Francisco Xavier, 524, $1^{\circ}$ andar bloco D, sl.1001 • Tels.: +55 21 2334-4088 / 4087 • http://www.e-publicacoes.uerj.br/index.php/polemica/index http://www.labore.uerj.br • laboreuerj@yahoo.com.br 
a posição que se ocupa na estrutura da sociedade influencia diretamente no julgamento de objetos e suas relações com indivíduos de outra posição na estrutura. A quinta causa é a Ideologia, onde representações ideologicamente marcadas (acerca da justiça, igualdade, mérito) influenciariam no posicionamento acerca das cotas. Portanto, os posicionamentos não ocorrem apenas de forma individual e se sustentariam também a partir de causas psicossociais.

Palavras-chave: Cotas. Atitude. Pensamento social. Universitários.

\title{
THE RATIONALE OF THE POSITIONS ON QUOTAS: A THEORETICAL AND EMPIRICAL SURVEY OF BRAZILIAN STUDENTS IN THE 21ST CENTURY
}

\begin{abstract}
This article proposes a discussion about the positions about quotas. A review of the literature was realized with the purpose of raising arguments favorable and against quotas, from studies in four areas of the Human Sciences (social psychology, anthropology, sociology and education) published in Brazil from the 2000s with a focus on the positioning of college students. are mainly based on problems arising from the difficulty of allocating quotas, while the favorable arguments are the effectiveness of quotas and their purpose of historical and social repair. Possible causes that lead groups of people to position themselves in relation to quotas have been verified: the first cause is related to the previous individual experiences, which occur when the fact of living or witnessing discrimination in relation to minorities marks the individuals and makes them be favorable or against the subject; the second cause corresponds to the right to the benefit, since the fact that the subject may or may not benefit from quotas would have an influence on the position of the measure. The third cause would be proximity to the quota students, which corresponds to the approximation of the subject with people in the personal circle who are quota students; the fourth cause would be structural homology, so that the position that a group occupies in the structure of society directly influences the judgment of objects and their relations with individuals of another position in the structure. The fifth cause is Ideology, where ideologically marked representations (about justice, equality, merit) would influence the positioning of dimensions. Therefore, the positioning does not only occur individually and would also be sustained from psychosocial causes.
\end{abstract}

Keywords: Quotas. Attitude. Social thought. College students.

\section{Introdução: ações afirmativas e cotas}

O presente artigo propõe uma reflexão teórica acerca dos argumentos relativos a posicionamentos de brasileiros, principalmente estudantes universitários, referentes às cotas ou ao sistema de reserva de vagas nas Universidades, a partir de trabalhos empíricos e teóricos das Ciências Humanas, como a Psicologia Social, Antropologia, Sociologia e Educação, que tenham sido publicados no Brasil a partir dos anos 2000. O estudo também considerou trabalhos que tratavam de argumentos de docentes e pré-vestibulandos.

Cabe ressaltar que as cotas estão inseridas no contexto das ações afirmativas, que podem ser caracterizadas como a saída da posição de neutralidade de um Estado para uma postura ativa na qual este leva em consideração fatores relativos à pertença do indivíduo ao elaborar suas políticas governamentais (GOMES, 2003). Elas podem ser definidas como:

um conjunto de políticas públicas e privadas de caráter compulsório, facultativo ou voluntário, concebidas com vistas ao combate à discriminação racial, de gênero, por deficiência física e de origem nacional, bem como para corrigir ou mitigar os efeitos presentes da discriminação praticada no passado, tendo por objetivo a concretização do ideal de efetiva igualdade de acesso a bens fundamentais como a educação e o emprego. (GOMES, 2003, p. 9).

\section{POLÊM!CA $\mid$ LABORE}

Polêmica - Revista Eletrônica da Uerj - Rua São Francisco Xavier, 524, $1^{\circ}$ andar bloco D, sl.1001 • Tels.: +55 21 2334-4088 / 4087 • http://www.e-publicacoes.uerj.br/index.php/polemica/index http://www.labore.uerj.br • laboreuerj@yahoo.com.br 
Alguns autores relacionam essas ações exclusivamente ao Estado e às políticas públicas, outros também às políticas privadas, mas independente de algumas diferenças, de uma maneira geral, os autores concordam no que se refere à busca por condições igualitárias e reparadoras para determinadas minorias (CAZELLA, 2012). Dentro dessa perspectiva, as ações afirmativas estão presentes essencialmente em sociedades democráticas que visam e também atuam de forma a promover a igualdade entre seus membros. Essa igualdade pode nunca ter existido ou, então, pode ter sido rompida ao longo da história dessa sociedade (MOEHLECKE, 2002).

Essas ações podem ser voluntárias ou de caráter obrigatório, de cunho governamental ou privado, envolvendo reservas de vagas para determinado grupo de pessoas ou apenas promovendo meios para acesso delas no mercado de trabalho, educação, saúde, representação política... Enfim, as ações afirmativas adquiriram diversas feições, mas estão sempre voltadas para melhorar as condições vivenciadas por minorias prejudicadas, como negros e mulheres (MOEHLECKE, 2002).

Também são alvos das ações erradicar as discriminações provenientes do passado e originar representatividade, atribuindo aos membros das minorias acesso a espaços que geralmente são acessíveis apenas à grupos privilegiados, tanto na esfera pública quanto privada (MOEHLECKE, 2002; GOMES, 2003). Desta forma, haveria reais chances de que indivíduos discriminados e prejudicados pudessem obter mobilidade social (GOMES, 2003).

O sistema de reserva de vagas ou cotas é um tipo de ação afirmativa e "consiste em estabelecer um determinado número ou percentual a ser ocupado em área específica por grupo(s) definido(s), o que pode ocorrer de maneira proporcional ou não, e de forma mais ou menos flexível”' (MOEHLECKE, 2002, p. 199). No geral, os grupos cujas vagas reservadas são destinadas incluem minorias subordinadas e excluídas de alguma forma ao longo da história. É o caso de negros e indígenas, entre outros grupos, que, segundo esta política, necessitam de meios compensatórios para que as consequências das desigualdades sofridas no passado sejam mitigadas.

As cotas são relativamente novas, de modo que no século passado haviam poucos exemplos de implementação dessas medidas, mas pouco a pouco elas foram ganhando espaço. No Brasil, em 1995, as cotas começam a ser instituídas com políticas de reserva de vagas para mulheres em cargos políticos. Já no ano de 1996, foi lançado o Programa Nacional dos Direitos Humanos, que direcionaram parte do foco das ações afirmativas e das cotas para o acesso da

\section{POLÊM!CA $\mid$ LABORE}

Polêmica - Revista Eletrônica da Uerj - Rua São Francisco Xavier, 524, $1^{\circ}$ andar bloco D, sl.1001 • Tels.: +55 21 2334-4088 / 4087 • http://www.e-publicacoes.uerj.br/index.php/polemica/index http://www.labore.uerj.br • laboreuerj@yahoo.com.br 
população negra ao campo educacional, nas universidades, cursos profissionalizantes e áreas de tecnologia de ponta (MOEHLECKE, 2002).

Como resultado desse processo, no dia 29 de agosto de 2012, a Lei das Cotas (Lei n ${ }^{\circ}$ 12.711) foi sancionada pela Presidente Dilma Rousseff, fazendo das cotas não apenas medidas voltadas às universidades, mas também institutos e centros federais. Essa lei afirma que, no mínimo, metade das vagas oferecidas anualmente por essas instituições sejam voltadas para determinadas minorias.

Na descrição de um breve histórico sobre as cotas no campo da educação cabe ressaltar que reservas de vagas destinadas a determinados grupos sociais já eram implementadas no século XIX. Exemplo disso é o acesso direto dos alunos de bacharelado em Letras do Colégio Pedro II a cursos superiores no ano de 1843 e em 1949. Outro exemplo é a concessão do acesso ao primeiro ano do curso de jornalismo a profissionais jornalistas que tivessem carteira de trabalho expedida pelo Ministério do Trabalho, sendo necessária somente uma prova de sanidade (DE ALMEIDA, 2010).

As cotas voltadas especificamente para etnias surgiram por conta da pressão das organizações negras frente ao governo. A demanda dessas organizações surgiu ao mesmo tempo em que ocorria o centenário da abolição da escravatura nos anos 80 e desde então estas passaram a exigir medidas ativas em prol dos negros no país (GUIMARÃES, 2003). Como consequência da pressão do movimento negro, o citado Programa Nacional dos Direitos Humanos foi lançado em 1996 com o foco de promover acesso de negros à educação. Com isso foram desenvolvidas leis que somente a partir de 2001 começaram a ser aprovadas (MOEHLECKE, 2002).

Em decorrência dessas leis, a reserva de vagas com critério racial nas universidades brasileiras começou a ser implementada em 2002 na Universidade do Estado da Bahia (MENDES, 2011). No ano seguinte, em 2003, a Universidade do Estado do Rio de Janeiro (PINTO, 2006) e a Universidade de Brasília (BELCHIOR, 2006; MENDES 2011) também aderiram à política de cotas.

Alguns trabalhos demonstram que as políticas de ações afirmativas e das cotas são bastante polêmicas e envolvem posicionamentos polarizados (MARTINS, 2004; QUEIROZ, SANTOS, 2006; NEVES, LIMA, 2007; NERY, COSTA, 2009). Os posicionamentos extremos

\section{POLÊM!CA | LABORE}

Polêmica - Revista Eletrônica da Uerj - Rua São Francisco Xavier, 524, $1^{\circ}$ andar bloco D, sl.1001 • Tels.: +55 21 2334-4088 / 4087 • http://www.e-publicacoes.uerj.br/index.php/polemica/index http://www.labore.uerj.br • laboreuerj@yahoo.com.br 
decorrem de divergências ao avaliar aspectos teóricos e práticos desta política, como a noção de igualdade e a eficácia destas medidas.

Sendo assim, o presente artigo tem por objetivo elucidar os principais argumentos presentes na literatura de quatro áreas das Ciências Humanas (psicologia social, antropologia, sociologia e educação), em produções decorrentes de estudos feitos majoritariamente com estudantes universitários, mas também com pré-vestibulandos e docentes que são favoráveis ou desfavoráveis às cotas no ambiente universitário.

\section{Método}

Esse artigo foi elaborado a partir de uma revisão de literatura na base Lilacs, Scielo e Google acadêmico, no período entre 2000 e 2015. As palavras-chaves foram "ação afirmativa", "cotas" e "estudantes universitários", além de suas correspondências em inglês "quotas", "affirmative action" e "university students". O critério de exclusão foi a ausência de descrição explícita do posicionamento em favorável, desfavorável ou neutro dos participantes referente às cotas no corpo do artigo e/ou ausência de argumentos favoráveis ou desfavoráveis às mesmas. Também foram excluídos trabalhos que não pertencem aos grupos de ciências humanas delimitados: psicologia social, antropologia, sociologia e educação.

Foram encontrados 71 artigos ao total nas bases de dados, mas alguns se repetiram entre as bases e outros não preenchiam os critérios deste estudo e foram desconsiderados da revisão de literatura. Sendo assim, foram selecionados 19 artigos teóricos e empíricos contendo posicionamentos explícitos e/ou argumentos de brasileiros.

O conteúdo dos diferentes posicionamentos relativos às cotas na universidade se reflete por meio de argumentos característicos dos brasileiros (QUEIROZ, SANTOS, 2006), principalmente dos grupos de estudantes universitários (SILVA, SILVA, 2012; NAIFF, NAIFF, SOUZA, 2009; NEVES, LIMA, 2007; COSTA, 2010; LIMA, NEVES, SILVA, 2014; MARQUES, SANTOS, 2015), mas também de docentes (SILVA, SILVA, 2012) e prévestibulandos (NEVES, LIMA, 2007) a partir de estudos empíricos e teóricos das Ciências Humanas aqui especificadas.

Esse levantamento teve o objetivo de elencar os estudos que foram realizados, a população investigada por esses estudos e também o posicionamento preponderante dessa população. Por esse motivo, os resultados serão expostos em tabelas que informam esses

\section{POLÊM!CA $\mid$ LABORE}

Polêmica - Revista Eletrônica da Uerj - Rua São Francisco Xavier, 524, $1^{\circ}$ andar bloco D, sl.1001 • Tels.: +55 21 2334-4088/4087 • http://www.e-publicacoes.uerj.br/index.php/polemica/index http://www.labore.uerj.br • laboreuerj@yahoo.com.br 
aspectos de cada estudo. Também serão elencados os principais argumentos favoráveis e contrários ao sistema de cotas que foram extraídos dos estudos elencados acima.

\section{O pensamento social acerca das cotas demonstrado em estudos empíricos}

O trabalho de Queiroz e Santos (2006) apresenta os resultados de dois momentos distintos do pensamento social de brasileiros em relação às cotas a partir do Datafolha. Parte da investigação foi feita quando as cotas nas universidades ainda não haviam sido implementadas, em 1995, e outra quando estas já estavam em vigor, em 2006.

A pesquisa do Datafolha de 1995, quando não haviam cotas nas universidades, mostra números muito próximos entre si nos dois polos de posicionamento, onde $49 \%$ dos entrevistados discordam e $48 \%$ concordam com as cotas em geral nas universidades, enquanto os outros $3 \%$ não sabem ou escolheram não se posicionar. Já os resultados de 2006, com as cotas já em vigor, mostram que $65 \%$ dos brasileiros eram favoráveis às cotas voltadas para negros e esse número sobe para $87 \%$ quando as cotas surgem atreladas a pessoas que possuem baixa renda.

Embora os resultados relativos aos posicionamentos do primeiro e do segundo momento da pesquisa sejam diferentes, em ambos o aumento do grau de discordância pelas cotas acompanha o aumento dos níveis de renda e escolaridade dos participantes (QUEIROZ, SANTOS, 2006).

A investigação de Silva e Silva (2012) sobre as representações sociais de universitários da Universidade Federal da Bahia (UFBA) acerca do mesmo tema apresentou nos resultados um discurso ambíguo por parte dos estudantes, mesclando aspectos positivos e negativos e também a estereotipização dos alunos beneficiados por cotas, vistos como um grupo homogêneo que possui uma série de dificuldades relacionadas a universidade.

Resultados contrários às cotas e contraditórios envolvendo universitários também são apresentados na pesquisa de Naiff, Naiff e Souza (2009), realizada na Universidade Federal Rural do Rio de Janeiro (UFRRJ). Em seus resultados são encontradas justificativas da implementação das cotas para negros/pardos, mas sobretudo, uma atitude majoritariamente contrária a estas, na qual surgiram elementos como racismo e preconceito.

Um outro estudo realizado com 240 universitários da Universidade do Estado do Rio de Janeiro (UERJ) demonstrou que a maioria dos estudantes possui uma atitude em geral

\section{POLÊM!CA $\mid$ LABORE}

Polêmica - Revista Eletrônica da Uerj - Rua São Francisco Xavier, $524,1^{\circ}$ andar bloco D, sl.1001 • Tels.: +55 21 2334-4088 / 4087 • http://www.e-publicacoes.uerj.br/index.php/polemica/index http://www.labore.uerj.br • laboreuerj@yahoo.com.br 
desfavorável às cotas raciais, ressaltando elementos como preconceito e racismo (COSTA, 2010).

Neves e Lima (2007), em sua pesquisa com mais de mil sujeitos da Universidade Federal de Sergipe (UFS), também demonstram que há uma grande rejeição às cotas raciais por parte dos universitários. Aproximadamente $80 \%$ deles apresentaram uma atitude negativa às cotas para negros, $12 \%$ uma atitude positiva e $9 \%$ não se posicionaram. A discordância em relação às cotas para estudantes de escola pública é mais baixa: quase $56 \%$ dos participantes tiveram uma atitude negativa, $35 \%$ uma atitude positiva e $10 \%$ não se posicionaram. Apesar das cotas para estudantes de escola pública possuírem uma rejeição menor do que as cotas raciais para negros, ambas são rejeitadas pelos estudantes da UFS.

No que se refere aos pré-vestibulandos de um curso em Aracaju, também em Sergipe, a maioria, $65 \%$, é desfavorável às cotas para pardos e negros em universidades públicas, enquanto $18 \%$ apoia as medidas e $15 \%$ não soube ou escolheu não se posicionar (NEVES, LIMA, 2007).

Outra pesquisa de Lima, Neves e Silva (2014) realizada com estudantes da Universidade Federal de Sergipe (UFS), antes da implementação maciça das cotas nas universidades federais em âmbito nacional, mostrou que os universitários concordam que a situação social dos negros é pior que a dos brancos no país. Todavia, no que se refere a esses resultados, os brancos (escore 3,50 em uma escala que varia de 1 - totalmente justa a 4 - totalmente injusta) expressam mais reconhecimento dessa injustiça do que os próprios negros (escore 2,80 em uma escala que varia de 1 - totalmente justa a 4 - totalmente injusta) prejudicados.

Ainda sobre a mesma pesquisa, apesar dos resultados citados, os estudantes da UFS, no momento anterior à implementação das cotas na instituição, se mostraram contrários às cotas sociais $(67 \%)$ e às cotas raciais $(83 \%)$. Depois da implementação das cotas, nova coleta de dados foi realizada a fim de verificar se houve mudança após o contato com os cotistas. Os resultados mostraram queda dos posicionamentos contrários referentes às cotas sociais, que passaram de $67 \%$ para $54 \%$. Já a rejeição às cotas raciais aumentou, passou de $83 \%$ para 94\%; esses números somados aos dos participantes sem posicionamentos (6\%), revelam a inexistência de participantes favoráveis nesta etapa da pesquisa (LIMA, NEVES, SILVA, 2014).

Lima et al (2014) trazem a noção de paternalismo para explicar os dados obtidos em sua pesquisa. O que ocorreria seria o reconhecimento e o desejo paterno de proteger essa minoria

\section{POLÊM!CA $\mid$ LABORE}

Polêmica - Revista Eletrônica da Uerj - Rua São Francisco Xavier, $524,1^{\circ}$ andar bloco D, sl.1001 • Tels.: +55 21 2334-4088/4087 • http://www.e-publicacoes.uerj.br/index.php/polemica/index http://www.labore.uerj.br • laboreuerj@yahoo.com.br 
prejudicada, mas ao mesmo tempo uma falta de ação, já que estes não almejam perder sua posição dominante.

Marques e Santos (2015) buscaram entender a noção de justiça dos jovens em relação as cotas raciais. Os participantes da pesquisa eram graduandos da Universidade do Estado do Rio de Janeiro (UERJ), da Universidade Federal de Uberlândia (UFU) e Universidade Federal Rural do Rio de Janeiro (UFRRJ). Os resultados mostram que tanto os sujeitos favoráveis quanto os desfavoráveis as cotas utilizavam do argumento de igualdade. Enquanto os favoráveis defendiam as medidas como uma forma de equiparar desigualdades, o outro polo de posicionamento alega que elas ferem o direito básico à igualdade.

Tabela - 1: Posicionamentos majoritários de brasileiros, estudantes e docentes universitários e pré-vestibulandos em relação às cotas presentes em estudos

\begin{tabular}{ccc}
\hline Autores do estudo & População & Posicionamento majoritário \\
\hline Queiroz e Santos (2006) & Brasileiros & Favorável às cotas raciais e sociais \\
\hline Silva e Silva (2012) & $\begin{array}{c}\text { Universitários e docentes } \\
\text { (UFBA) }\end{array}$ & Ambivalente \\
\hline Naiff, Naiff e Souza (2009) & Universitários (UFRRJ) & Desfavorável às cotas raciais \\
\hline Neves e Lima (2007) & $\begin{array}{c}\text { Pré-vestibulandos } \\
\text { (Aracaju - SE) }\end{array}$ & Desfavorável às cotas raciais \\
\cline { 2 - 3 } Costa (2010) & Universitários (UFS) & Desfavorável às cotas raciais e sociais \\
\hline Lima, Neves e Silva (2014) & Universitários (UERJ) & Desfavorável às cotas raciais e \\
ambivalentes às sociais
\end{tabular}

Fonte: $\mathrm{O}$ autor.

Considerando o estudo de Queiroz e Santos (2006) realizado a partir do Datafolha, enquanto grande parte dos brasileiros apoia as cotas, os universitários de diversas partes do país, em sua maioria, são desfavoráveis a estas. Os estudos demonstram que essa atitude desfavorável está mais relacionada às cotas raciais, enquanto que as cotas sociais possuem uma aceitação maior.

Justas ou não, as cotas (Lei n $\left.{ }^{\circ} 12.711 / 12\right)$ já garantiram a matrícula de aproximadamente 150 mil estudantes negros no Ensino Superior, de acordo a Secretaria Nacional de Políticas de Promoção da Igualdade Racial - SEPPIR (2016). O SEPPIR (2016) também afirma que a Lei de cotas é cumprida por 128 instituições federais de ensino e as discussões em torno da medida

\section{POLÊM!CA | LABORE}

Polêmica - Revista Eletrônica da Uerj - Rua São Francisco Xavier, 524, $1^{\circ}$ andar bloco D, sl.1001 • Tels.: +55 21 2334-4088 / 4087 • http://www.e-publicacoes.uerj.br/index.php/polemica/index http://www.labore.uerj.br • laboreuerj@yahoo.com.br 
abrangem não só os universitários, mas sim outros tipos de estudantes, intelectuais, políticos e muitos brasileiros.

\section{Argumentos levantados na literatura relacionados à rejeição das cotas}

Conforme observado no subtópico anterior, existem diversos grupos que são contrários à adoção das cotas no Ensino Superior no Brasil. Essa atitude negativa é pautada por argumentos e opiniões diversas. Munaga (2001) apresenta que as cotas seriam rejeitadas por argumentos como o abandono das políticas de ação afirmativa nos Estados Unidos; pelas cotas não serem também destinadas aos índios; e pelos próprios negros beneficiados poderem prejudicar sua imagem profissional pelo fato de se formarem como cotistas.

Queiroz e Santos (2006) realizaram um estudo com docentes da Universidade Federal da Bahia (UFBA), que apresentaram argumentos contrários às cotas pautados na questão da miscigenação no Brasil. Essa questão é frequentemente levantada pelos críticos às cotas, pois para eles é árduo no nosso país classificar alguém pela sua cor (BENTO, 2005). Além disso, a autodeclaração traz a questão do benefício impróprio de algumas pessoas (PINTO, 2006; OLIVEN, 2007).

Além disso, a pesquisa (QUEIROZ, SANTOS, 2006) também demonstrou argumentos que afirmam que a verdadeira questão dos negros é econômica e por isso as cotas seriam medidas que abafam a real causa do problema. Ou seja, a reserva de vagas também é atacada pela justificativa de que a verdadeira raiz do problema das minorias está relacionada à pobreza e que as cotas não seriam medidas eficientes, já que não resolveriam esse problema central (BENTO, 2005; PINTO, 2006).

Os docentes da UFBA que participaram desse estudo (QUEIROZ, SANTOS, 2006) também ressaltam que o mérito é a marca do acesso ao Ensino Superior e que as cotas ferem a meritocracia. Além disso, facilitar a entrada na universidade de alunos oriundos de um ensino básico precário poderia ocasionar a perda de qualidade do ensino (GUIMARÃES, 2003). Outro fator é que os beneficiados pelo sistema de cotas abandonariam os cursos pela impossibilidade de atender às exigências de rendimento acadêmico, de modo que seria necessário investir no ensino público de qualidade e não em cotas nas universidades (OLIVEN, 2007).

Estudos como os de Bento (2005), Gomes (2008) e Pereira (2008) afirmam que grande parte das pessoas desfavoráveis à política de cotas adere à ideia de que esta fere o princípio de

\section{POLÊM!CA | LABORE}

Polêmica - Revista Eletrônica da Uerj - Rua São Francisco Xavier, $524,1^{\circ}$ andar bloco D, sl.1001 • Tels.: +55 21 2334-4088 / 4087 • http://www.e-publicacoes.uerj.br/index.php/polemica/index http://www.labore.uerj.br • laboreuerj@yahoo.com.br 
igualdade. $\mathrm{O}$ artigo $5^{\circ}$ da Constituição brasileira garante que “todos são iguais perante a lei” e, nesse sentido, a medida fere a premissa por atribuir tratamento diferenciado entre os grupos sociais.

É o caso dos estudantes da UFS que participaram do estudo de Lima, Neves e Silva (2014), que apresentaram, como argumento para justificar a rejeição às cotas, o aumento do preconceito relacionado aos estudantes que ingressaram pelo sistema de cotas e a ameaça à igualdade entre os candidatos na concorrência pelas vagas nas universidades.

Todavia, nem sempre a rejeição às cotas é total. Marques e Santos (2015) ressaltam em sua pesquisa que estudantes universitários desfavoráveis às cotas raciais apresentam com frequência aceitação das cotas sociais.

Tabela - 2: Principais argumentos apresentados por teóricos das Ciências humanas (psicologia social, antropologia, sociologia e educação) em estudos empíricos realizados com estudantes e docentes universitários e pré-vestibulandos que rejeitam as cotas

\section{Principais argumentos relacionados à rejeição das cotas}

Isonomia, Pobreza e Miscigenação (BENTO, 2005; OLIVEN, 2007; ALMEIDA, 2007)

Os negros beneficiados pelas cotas poderiam prejudicar a imagem profissional (MUNANGA, 2001)

Perda do mérito (GUIMARÃES, 2003)

Problemas ao longo do curso por conta do histórico do ensino precário da rede pública (QUEIROZ,

SANTOS, 2006)

Interferência no princípio de igualdade garantido pela Constituição (BENTO, 2005; GOMES, 2008

PEREIRA, 2008; LIMA, NEVES, SILVA, 2014)

Benefício impróprio de algumas pessoas (PINTO, 2006; ALMEIDA, 2007; OLIVEN, 2007).

Abandono das políticas de ação afirmativa nos Estados Unidos (MUNANGA, 2001)

É necessário investir no ensino público ao invés de criar cotas (OLIVEN, 2007)

O passado das minorias não interfere no presente (MARQUES, SANTOS, 2015)

Fonte: $\mathrm{O}$ autor.

Como visto na Tabela 2, os argumentos contrários à medida de cotas abarcam questões teóricas, como, por exemplo, a ideia de igualdade, e também consideram questões práticas, como as consequências negativas que podem ocorrer tanto com os beneficiados quanto com a instituição que adere às cotas.

\section{POLÊM!CA $\mid$ LABORE}

Polêmica - Revista Eletrônica da Uerj - Rua São Francisco Xavier, 524, $1^{\circ}$ andar bloco D, sl.1001 • Tels.: +55 21 2334-4088 / 4087 • http://www.e-publicacoes.uerj.br/index.php/polemica/index http://www.labore.uerj.br • laboreuerj@yahoo.com.br 


\section{Argumentos levantados na literatura relacionados à aceitação das cotas}

Se os argumentos contrários enfatizam, em sua maioria, a noção de igualdade e consequências ruins das cotas, os argumentos favoráveis, por sua vez, referem-se, em geral, à finalidade e eficácia das medidas.

As pessoas favoráveis a essa política costumam defender seu ponto de vista a partir de estudos que mostram a baixa escolaridade, o alto índice de desemprego e as más condições de moradia de pardos e negros em relação aos brancos, de modo a contextualizar a situação desses grupos e demonstrar que necessitam desse tipo de medida. Dados apontam que a renda média de um homem negro já chegou a ser menos da metade da renda de um homem branco e a taxa de analfabetismo duas vezes maior na população negra (LARKIN NASCIMENTO, 2003).

No caso específico das universidades, ao defender as cotas, muitas pessoas salientam que elas são uma forma de acesso ao meio intelectual universitário, o que por sua vez auxiliaria na criação de uma elite negra no país (PINTO, 2006). Esse argumento é corroborado ao observar que o número de pessoas pobres ou negras que ingressaram no Ensino Superior é muito baixo. Outra justificativa é que por motivos históricos relacionados aos negros e indígenas, como mortes e escravidão, essas minorias passam por uma exclusão social que necessita ser encerrada, e assim o Estado precisa intervir em prol dessas minorias (MOEHLECKE, 2002; OLIVEN, 2007).

A contribuição de Oliven (2007) aponta que a defesa das cotas em cursos superiores é calcada na ideia de respeito às diferenças culturais na sociedade, que influenciam diretamente as relações entre os grupos sociais. Assim, as pessoas a favor argumentam-nas como principal meio para combater a desigualdade social.

Tal desigualdade pode ser constatada não apenas no acesso de determinados grupos sociais à universidade como também na porcentagem de docentes negros nas universidades públicas no país, pois, como Carvalho (2005) ressalta, a média de docentes negros e pardos é extremamente baixa, inferior a $1 \%$. Ao pesquisar a representatividade negra em docentes universitários, o autor observou dados alarmantes, como o percentual de professores negros na Universidade de São Paulo, 0,10\%; Universidade Federal do Rio Grande do Sul, 0,15\%; Universidade Estadual de Campinas, 0,20\%; Universidade Federal do Rio de Janeiro, 0,60\%; Universidade Federal de Minas Gerais, 0,70\%; e Universidade de Brasília, 1,00\%.

\section{POLÊM!CA $\mid$ LABORE}

Polêmica - Revista Eletrônica da Uerj - Rua São Francisco Xavier, 524, $1^{\circ}$ andar bloco D, sl.1001 • Tels.: +55 21 2334-4088 / 4087 • http://www.e-publicacoes.uerj.br/index.php/polemica/index http://www.labore.uerj.br • laboreuerj@yahoo.com.br 
Outros dados e estudos mais atuais (CRUZ, 2016; MARTINS, 2017; PIRES, 2014) demonstram que o número de docentes negros ainda é baixo no Ensino Superior público brasileiro, isso fica claro quando se nota que o padrão dos dados de Carvalho (2015) não é muito diferente do apresentado por Martins (2017) e Pires (2014), apesar de aproximadamente uma década ter se passado.

Os participantes do estudo de Lima, Neves e Silva (2014) bem como do estudo de Marques e Santos (2015) apresentaram, como argumento favorável, que as cotas possibilitam a justiça social e diminuem o preconceito, isso além de promover igualdade. Outras questões levantadas estão associadas a oportunidades iguais entre as pessoas na sociedade, aumento da possibilidade de ascensão e inclusão social. As cotas, nessa perspectiva, são uma ferramenta válida na inserção não só no meio universitário, mas também na vida profissional do negro.

Tabela - 3: Principais argumentos apresentados por teóricos das Ciências humanas (psicologia social, antropologia, sociologia e educação) em estudos empíricos realizados com estudantes universitários que aceitam as cotas

\section{Principais argumentos relacionados à aceitação das cotas}

Tentativa de proporcionar mais acesso de minorias prejudicadas ao longo da história (MOEHLECKE, 2002;

OLIVEN, 2007; ALMEIDA, 2007)

Tanto os negros quanto os indígenas foram reprimidos no passado (MOEHLECKE, 2002; OLIVEN, 2007)
Promovem acesso a meios fundamentais como educação e melhor inserção social (MARQUES, SANTOS,
2015)
Possibilitam a justiça social (LIMA, NEVES, SILVA, 2014; MARQUES, SANTOS, 2015)
Diminuem o preconceito (LIMA, NEVES, SILVA, 2014)

São medidas válidas para promover igualdade (LIMA, NEVES, SILVA, 2014; MARQUES, SANTOS, 2015)

Aumento da representatividade negra (CARVALHO, 2005; OLIVEN, 2007)

Baixa escolaridade, alto índice de desemprego e más condições de moradia dos negros se comparados aos brancos (PINTO, 2006)

São o principal meio para combater as desigualdades sociais (OLIVEN, 2007)

Fonte: $\mathrm{O}$ autor.

Como visto na Tabela 3, a aceitação das cotas é marcada por argumentos que ressaltam a finalidade da medida, como o combate às injustiças sociais; além disso, abarcam causas que a tornam necessária, como a discrepância social entre as etnias e consequências positivas ligadas a eficácia social destas, como a diminuição do preconceito.

\section{POLÊM!CA $\mid$ LABORE}

Polêmica - Revista Eletrônica da Uerj - Rua São Francisco Xavier, 524, $1^{\circ}$ andar bloco D, sl.1001 • Tels.: +55 21 2334-4088 / 4087 • http://www.e-publicacoes.uerj.br/index.php/polemica/index http://www.labore.uerj.br • laboreuerj@yahoo.com.br 


\section{Discussão e considerações finais}

Os diferentes conteúdos contidos nas defesas decorrentes de posicionamentos favoráveis e desfavoráveis em relação às cotas raciais podem ser compreendidos sob a ótica de Doise (1986/1990/2002). O autor defende que a visão do objeto social é diferente de acordo com a posição ocupada na sociedade. Assim, esses posicionamentos não ocorrem de forma individual, mas se sustentam a partir de posições ocupadas nas relações sociais, ou seja, o conteúdo de ideias referente ao objeto social depende das relações entre os grupos e do grupo cuja pessoa que o representa está inserida. Nesse sentido, Deschamps e Moliner (2009) afirmam que é possível realizar uma homologia entre a posição de um grupo no espaço social e a representação desse espaço que é criada por esse grupo.

Esse aspecto ponderado pelo autor pode ser verificado no conteúdo dos argumentos dos cotistas referentes à discrepância social, pois o grupo defensor das cotas vê as minorias como prejudicadas socialmente e ressalta outros grupos que não o são, e, a partir disso, faz julgamentos com a finalidade de reparo para essa desigualdade, ressaltando, sobretudo, a eficácia das cotas enquanto medidas de reparação e equiparação social.

Doise (2002) afirma que um grupo social percebe outro grupo acentuando suas diferenças, de modo a afirmar sua identidade social enquanto se diferente de outro grupo. Grupos que ocupam posições elevadas na sociedade tendem a modificar as relações e comportamentos com grupos menos consolidados, o que gera mais discriminação ao se referir a estes. Nessas relações assimétricas entre grupos, no qual um grupo se posiciona acima de outro na estratificação, o grupo que é dominante tende a se representar de maneira heterogênea e representam de maneira homogênea os grupos dominados. Esse fato leva aos grupos da alta classe a explicar os seus sucessos pelas suas potencialidades individuais e explicar o sucesso do outro apenas por sua pertença a um grupo (DESCHAMPS, MOLINER, 2009). Esse fator pode explicar alguns argumentos contrários às cotas, principalmente aqueles que estão pautados na quebra de meritocracia e da igualdade, já que favoreceriam essa visão do grupo de estudantes universitários de que o sucesso dos cotistas não são causados por fatores individuais, mas sim por sua pertença a um grupo minoritário específico.

Deschamps e Moliner (2009) também falam que na comparação social, quando os grupos estão lidando com uma comparação simétrica (observando outros grupos posicionados de maneira similar na estrutura social) tendem a dar explicações internas para fatores positivos

\section{POLÊM!CA $\mid$ LABORE}

Polêmica - Revista Eletrônica da Uerj - Rua São Francisco Xavier, 524, $1^{\circ}$ andar bloco D, sl.1001 • Tels.: +55 21 2334-4088 / 4087 • http://www.e-publicacoes.uerj.br/index.php/polemica/index http://www.labore.uerj.br • laboreuerj@yahoo.com.br 
e externas para fatores negativos relacionados ao grupo alvo de comparação. Quando a comparação é assimétrica (quando grupos que ocupam posições superiores ou inferiores na estratificação social são observados) os grupos tendem a dar explicações internas tanto para os fatores positivos, quanto para negativos.

Ao pensar na comparação social de estudantes universitários não cotistas se comparando com estudantes universitários cotistas, ela se mostraria enquanto uma relação assimétrica descendente (um grupo dominante observando um dominado), o que faria com o que os não cotistas considerassem as dificuldades enfrentadas pelos cotistas enquanto resultado de um fator individual interno e não externo. Esse fato pode explicar o argumento contrário às cotas que afirma que o passado de uma minoria não influencia o seu presente, já que isso seria uma explicação externa a uma atribuição negativa ao grupo de cotistas.

Ao observar os argumentos contrários às cotas apresentados na Tabela 2 é possível notar o efeito descrito no parágrafo acima, já que a maioria desses argumentos é pautada em fatores internos, como perda do mérito, prejuízo na imagem profissional do beneficiado pelas cotas e a intenção ruim de algumas pessoas que burlam o sistema de cotas. E também é interessante notar que os argumentos favoráveis às cotas raciais apresentados na Tabela 3 estão, em sua maioria, relacionados a fatores externos, como o fato dos negros terem sido mais prejudicados ao longo da história, do baixo nível de qualidade do ensino ao qual as minorias têm acesso, das desigualdades sociais sofridas pelos negros.

Vale ressaltar que existem outros fatores que podem influenciar na tomada de posicionamento frente às cotas. Existem explicações ora mais psicológicas, ora mais sociológicas, e também explicações abarcadas e articuladas a partir da junção dessas esferas.

Em suma, o grupo de universitários e docentes (maioria dos sujeitos abarcados pelos estudos abordados por esse trabalho) lidam diariamente com estudantes universitários cotistas em relações que são simétricas, quando cotistas observam cotistas, ou são assimétricas, quando docentes e não cotistas observam cotistas. É possível então inferir que a posição social dos grupos e suas relações cotidianas são fundamentais para a compreensão de como se formam os argumentos e posicionamentos contrários e favoráveis ao sistema de cotas.

Utilizando as formulações de Doise e de Deschamps e Moliner é possível pensar que as razões que levam grupos de pessoas a se posicionar favoravelmente ou contrariamente podem ser compreendidas em cinco categorias. A primeira consiste nas experiências individuais

\section{POLÊM!CA | LABORE}

Polêmica - Revista Eletrônica da Uerj - Rua São Francisco Xavier, 524, $1^{\circ}$ andar bloco D, sl.1001 • Tels.: +55 21 2334-4088 / 4087 • http://www.e-publicacoes.uerj.br/index.php/polemica/index http://www.labore.uerj.br • laboreuerj@yahoo.com.br 
prévias, quando o fato de conviver ou presenciar discriminação e preconceito em relação a minorias marca os indivíduos e faz com que militem a causa das cotas ainda que não possam se beneficiar das medidas. A segunda razão corresponderia ao direito ao benefício, ou seja, o fato do sujeito poder ou não se beneficiar do sistema de reserva de vagas traria uma influência no posicionamento que tem da medida. Uma terceira seria a proximidade com os cotistas, ou melhor, o quanto o sujeito possui aproximação com amigos, familiares, pessoas do círculo pessoal de contato que são a favor ou contra o sistema de cotas.

Na quarta razão, a homologia estrutural, pela qual a posição que se ocupa na estrutura da sociedade influencia diretamente no julgamento de objetos e suas relações com indivíduos de outra posição na estrutura. A quinta seria da ordem da Ideologia, que é a base do conjunto de representações que o grupo possui acerca de uma variedade de objetos. Estas representações ideologicamente marcadas (acerca da justiça, igualdade, mérito) influenciariam no posicionamento dos sujeitos acerca das cotas.

Estas explicações são passíveis de investigação e de fato complementam e auxiliam de forma fundamental a compreensão do posicionar-se frente às cotas, constituindo, portanto, possíveis ferramentas para o estudo do pensamento social referente ao objeto cotas e sua polêmica nas universidades brasileiras, uma vez que a política de cotas no meio universitário é recente e carece de investigações sérias que abarquem a totalidade do fenômeno. Estudos futuros que utilizem as diretrizes das teorias da identidade social e da teoria do pensamento social permitiriam observar além dos argumentos, posicionamentos e opiniões dos sujeitos e compreender melhor de que forma eles se constituem por fatores ideológicos, representacionais e de relação intergrupal.

\section{Referências}

BELCHIOR, E. B. Não deixando a cor passar em branco: o processo de implementação de cotas para estudantes negros na Universidade de Brasília. 2006. 137 f. Dissertação (Mestrado em Sociologia) Universidade de Brasília, Brasília, 2006. Disponível em:

<http://repositorio.unb.br/bitstream/10482/5554/1/2006_Ernandes\%20Barboza\%20Belchior.pdf>. Acesso em: 22 jul. 2017.

BENTO, M. A. S. Branquitude e poder: a questão das cotas para negros. Simpósio internacional do adolescente, São Paulo, mai. 2005.

CARVALHO, J. J. Inclusão étnica e racial no Brasil: a questão das cotas no ensino superior. São Paulo: Attar, 2005.

\section{POLÊM!CA $\mid$ LABORE}

Polêmica - Revista Eletrônica da Uerj - Rua São Francisco Xavier, 524, $1^{\circ}$ andar bloco D, sl.1001 • Tels.: +55 21 2334-4088 / 4087 • http://www.e-publicacoes.uerj.br/index.php/polemica/index http://www.labore.uerj.br • laboreuerj@yahoo.com.br 
CAZELLA, B. B. B. O sistema de cotas raciais para negros nas universidades públicas brasileiras. Espaço Jurídico, Santa Catarina, v. 13, n. 2, p. 373-392, 2012. Disponível em:

<http://editora.unoesc.edu.br/index.php/espacojuridico/article/view/1390/1120>. Acesso em: 22 jul. 2017.

COSTA, S. C. As representações sociais de estudantes universitários sobre o sistema de cotas para negros e alunos de escola pública. 2010. 198 p. Dissertação (Mestrado em Psicologia Social) - Faculdade de Psicologia da Universidade do Estado do Rio de Janeiro, 2010.

CRUZ, M. M. Número de professores negros em universidades públicas gera debate. Em, Minas Gerais, fev. 2016. Disponível em: <https://www.em.com.br/app/noticia/gerais/2016/02/03/interna_gerais,731244/numero-deprofessores-negros-em-universidades-publicas-gera-debate.shtml>. Acesso em: 21 ago. 2018.

DE ALMEIDA, S. M. L. Acesso à educação superior no brasil: direito ou privilégio? Revista HISTEDBR OnLine, Campinas, v. 10, n. 38, p. 169-185, 2010.

DESCHAMPS, J. C.; MOLINER, P. A identidade em psicologia social - Dos processos identitários às representações sociais. Petrópolis: Editora Vozes, 2009.

DOISE, W. Levels of explanation in social psychology. New York: Cambridge University Press, 1986.

Les représentations sociales. In: GHIGLIONE, R.; BONNET, C.; RICHARD, J. F. (Orgs.). Traité de psychologie cognitive. Paris: Dunod, 1990.

Da psicologia social à psicologia societal. Psicologia: teoria e pesquisa, Brasília, v. 18, n. 1, p. 27-35, 2002. Disponível em: <http://www.scielo.br/pdf/ptp/v18n1/a04v18n1>. Acesso em: 22 jul. 2017.

GOMES, J. B. O debate constitucional sobre as ações afirmativas. In: SANTOS, R.; LOBATO, F.(Orgs.). Ações afirmativas: políticas públicas contra as desigualdades raciais. Rio de Janeiro: DP\&A, 2003.

GOMES, F. S. A questão da igualdade e a política de cotas. Bahia, 2008. 131 f. Dissertação (Mestrado em Políticas Sociais e Cidadania) - Faculdade de Políticas Sociais da Universidade Católica do Salvador, Salvador, 2008.

GUIMARÃES, A. S A. Acesso de negro às Universidades Públicas. Cadernos de Pesquisa, São Paulo, v. 247 , n. 118, p. 247-268, 2003. Disponível em: 〈http://publicacoes.fcc.org.br/ojs/index.php/cp/article/view/535/537〉. Acesso em: 22 jul. 2017.

LARKIN NASCIMENTO, E. L. O Sortilégio da Cor. Identidade, Raça e Gênero no Brasil. São Paulo: Summus, 2003.

LIMA, M. E. O.; NEVES, P. S. C.; SILVA, P. B. A implantação de cotas na universidade: paternalismo e ameaça à posição dos grupos dominantes. Revista Brasileira de Educação, Rio de Janeiro, v. 19, n. 56, p. 141254, 2014. Disponível em:

<http://www.clam.org.br/bibliotecadigital/uploads/publicacoes/1832_151_limanevesv19n56a08.pdf>. Acesso em: 22 jul. 2017.

MARQUES, T.; SANTOS, B. K. A. dos. Um estudo sobre o pensamento social de jovens universitários acerca da justiça e das cotas raciais. Psicologia e Saber Social, Rio de Janeiro, v. 4, n. 1, p. 108-125, 2015. Disponível em: <http://www.e-publicacoes.uerj.br/index.php/psi-sabersocial/article/view/17559/12966>. Acesso em: 18 ago. 2018.

MARTINS, L. R. Perfil racial dos docentes da USP analisa baixo índice de professores negros. Agência Universitária de Notícias da USP, mar. 2017. Disponível em:

<https://paineira.usp.br/aun/index.php/2017/03/23/perfil-racial-dos-docentes-da-usp-analisa-baixo-indice-deprofessores-negros/>. Acesso em: 21 ago. 2018.

\section{POLÊM!CA $\mid$ LABORE}

Polêmica - Revista Eletrônica da Uerj - Rua São Francisco Xavier, 524, $1^{\circ}$ andar bloco D, sl.1001 • Tels.: +55 21 2334-4088 / 4087 • http://www.e-publicacoes.uerj.br/index.php/polemica/index http://www.labore.uerj.br • laboreuerj@yahoo.com.br 
MARTINS, A. R. N. A Polêmica construída: racismo e discurso da imprensa sobre a política de cotas para negros. 2004. 210 f. Tese (Doutorado em Linguística) - Faculdade de Linguística da Universidade de Brasília, Brasília, 2004.

MENDES, J. S. Rede de pesquisa para avaliação do sistema de cotas e ações afirmativas para negros e indígenas na educação superior pública. Anais do encontro de iniciação científica-enic, UEMS, Mato Grosso do Sul, Brasil, 2011.

MOEHLECKE, S. Ação afirmativa: História e debates no Brasil. Cad. Pesqui. [online], São Paulo, v. 117, n. 11, p. 197-217, 2002. Disponível em: 〈http://www.scielo.br/pdf/cp/n117/15559>. Acesso em: 22 jul. 2017.

MUNANGA, K. Políticas de ação afirmativa em benefício da população negra no Brasil: um ponto de vista em defesa das cotas. Sociedade e Cultura, Goiânia, v. 4, n. 2, p. 31-43, 2001. Disponível em: <http://www.redalyc.org/html/703/70311216002/>. Acesso em: jul. 2017.

NAIFF, D. G. M.; NAIFF, L. A. M.; SOUZA, M. A. As representações sociais de estudantes universitários a respeito das cotas para negros e pardos nas universidades públicas brasileiras. Estudos e Pesquisas em Psicologia, Rio de Janeiro, v. 9, n. 1, p. 216-229, 2009. Disponível em: <http://www.epublicacoes_teste.uerj.br/ojs/index.php/revispsi/article/view/9146/7019>. Acesso em: 22 jul. 2017.

NERY, M. P.; COSTA, L. F. Política afirmativa racial: polêmicas e processos de identidade do cotista universitário. PsicoUSF [online], Bragança Paulista, v. 14, n. 2, p. 211-220, 2009. Disponível em: <http://pepsic.bvsalud.org/scielo.php?script=sci_arttext\&pid=S1413-82712009000200010>. Acesso em: 22 jul. 2017.

NEVES, P.; LIMA, M. E. Percepções de justiça social e atitudes de estudantes pré-vestibulandos e universitários sobre as cotas para negros e pardos nas universidades públicas. Revista Brasileira de Educação, Rio de Janeiro, v. 12, n. 34, p. 17-38, 2007. Disponível em: 〈http://flacso.redelivre.org.br/files/2012/07/550.pdf\#page=58>. Acesso em: 22 jul. 2017.

OLIVEN, A. C. Ações afirmativas, relações raciais e política de cotas nas universidades: Uma comparação entre os Estados Unidos e o Brasil. Educação, Porto Alegre, v. 30, n. 61, p. 29-51, 2007.

PEREIRA, I. M. O discurso sobre a política de cotas raciais no jornalismo online. Fronteiras-estudos midiáticos, Rio de Janeiro, v. 10, n. 3, p. 173-182, 2008.

PINTO, P. G. H. R. Ação afirmativa, fronteiras raciais e identidades acadêmicas: uma etnografia das cotas para negros na Uerj. In: FERES JUNIOR, João; ZONISZEIN, Jonas (Orgs.). Ações afirmativas e universidade: experiências nacionais comparadas. Brasília: Ed. UnB, 2006.

PIRES, M. F. C. Docentes Negros na Universidade Pública Brasileira: docência e pesquisa como resistência e luta. Campinas, 2014. 200 p. Tese (Doutorado em Educação) - Universidade Estadual de Campinas, Campinas, 2014. Disponível em:

〈http://repositorio.unicamp.br/bitstream/REPOSIP/253910/1/Pires_MaraFernandaChiari_D.pdf >. Acesso em: 21 ago. 2018.

QUEIROZ, D. M.; SANTOS, J. T. Sistema de cotas: um debate. Dos dados à manutenção de privilégios e de poder. Educação e Sociedade, Campinas, v. 27, n. 96, p. 717-737, 2006.

SEPPIR - SECRETARIA NACIONAL DE POLÍTICAS DE PROMOÇÃO DA IGUALDADE RACIAL. Em 3 anos, 150 mil negros ingressaram em universidades por meio de cotas. SEPPIR, 21 mar. 2016. Disponível em: <http://www.seppir.gov.br/central-de-conteudos/noticias/2016/03-marco/em-3-anos-150-mil-negrosingressaram-em-universidades-por-meio-de-cotas>. Acesso em: 21 ago. 2018.

\section{POLÊM!CA $\mid$ LABORE}

Polêmica - Revista Eletrônica da Uerj - Rua São Francisco Xavier, 524, $1^{\circ}$ andar bloco D, sl.1001 • Tels.: +55 21 2334-4088 / 4087 • http://www.e-publicacoes.uerj.br/index.php/polemica/index http://www.labore.uerj.br • laboreuerj@yahoo.com.br 
SILVA, P. B.; SILVA, P. Representação Social de Estudantes Universitários sobre Cotas na Universidade. Fractal: Revista de Psicologia [online], Niterói, v. 24, n. 3, p. 525-542, 2012.

Recebido em: 09/08/2017.

Aceito em: 30/05/2018.

\section{POLÊM!CA $\mid$ LABORE}

Polêmica - Revista Eletrônica da Uerj - Rua São Francisco Xavier, 524, $1^{\circ}$ andar bloco D, sl.1001 • Tels.: +55 21 2334-4088 / 4087 • http://www.e-publicacoes.uerj.br/index.php/polemica/index http://www.labore.uerj.br • laboreuerj@yahoo.com.br 